\title{
Cluster Schools for Diverse Students’ Needs in Malaysia: A System View
}

\author{
Aziah Ismail (PhD) \\ School of Educational Studies, University Sains Malaysia \\ 11800 Pulau Pinang, Malaysia \\ E-mail: aziah@usm.my \\ Abdul Ghani Abdullah (PhD) (Corresponding author) \\ School of Educational Studies, University Sains Malaysia \\ 11800 Pulau Pinang, Malaysia \\ E-mail: agk@usm.my
}

Received: August 9, 2011 Accepted: October 19, 2011 Published: December 31, 2011

doi:10.5296/ije.v3i2.1282ＵRL: http://dx.doi.org/10.5296/ije.v3i2.1282

\begin{abstract}
This study aims to examine the role of the cluster schools in Malaysia in order to meet the diverse needs of students. It also seeks to identify the efforts that were initiated by the cluster schools in managing the sustainability of their niche areas to be in line with their students' needs. Data was collected using interviews and documents analysis which are related to six cluster schools in Malaysia from different excellent clusters. The findings showed that the niche areas of each cluster schools were selected based on their students' excellence in academic, curricular or personality areas. Thus, the niche area of each cluster school is different from the others. This indicates that the interest and propensity of students in cluster schools are tailored with the creation and selection of different niche areas for each school. In addition, the study also showed that the cluster schools have organized various programs and activities to accelerate their students' excellence in their particular niche areas. There are also programs and activities which were initiated by the students at national as well as international levels. Results obtained from this study proved that the creation of cluster schools in Malaysia is not just to accelerate the organizational excellence per se, but also to focus on the needs of diverse students. This is also strengthened by the efforts of the schools to accelerate their students' excellence in their particular niche areas.
\end{abstract}

Keywords: Malaysian cluster schools, Diversity, Students' needs, Education development plan 


\section{Introduction}

The development of the education system is closely linked to the social, economic and political needs of the country. Hence, the education system plays a vital role in realizing the nation's aspirations to develop within these three spheres the quality of their human capital (Fagerlind \& Saha, 1989). In Malaysia, the implementation of the Education Development Master Plan (EDMP) 2006-2010 on 16 January 2006 has been seen as a step towards providing quality education for all children and producing quality human capital for the country (Ministry of Education, 2006a). The plan has outlined six strategic thrusts including the thrust of Accelerating Excellence in Educational Institutions of Malaysia. Based on this thrust, some excellent schools were and will be selected and recognized as cluster schools of excellence (CSE), cohort by cohort, and obtained some degree of autonomy to accelerate their organizational excellence (Ministry of Education, 2006). This action was in line with the 9th Malaysia Plan (9MP) from 2006 to 2010, which has placed great importance on education, training and lifelong learning (Malaysia, 2006).

The implementation of the CSE concept in Malaysia was aimed at spurring outstanding schools in this country to achieve world-class standards and become internationally recognized (Ministry of Education, 2006a). Cluster schools is a brand name given to the selected schools in Malaysia which have been identified as being excellent within their cluster from the aspect of school management and students excellence (Ministry of Education, 2006b). It also refers to the selected schools which have the potential to be excellent in their respective clusters and to fulfill the prerequisites set by the Ministry of Education (MoE) Malaysia. Presently there are 120 schools from 9,943 schools in Malaysia recognized as CSE (Ministry of Education, 2010). In the selection process, the cluster schools are assessed and evaluated based on their excellence in respective clusters as follows:

- $\quad$ Primary Schools: National Schools (SK), Chinese National Type Schools (SJKC), Tamil National Type Schools (SJKT) and the Indigenous Schools.

- $\quad$ Secondary Schools: Fully Residential Schools (SBP), Technical Secondary Schools (SMT), National Religious Secondary Schools (SMKA), Daily Secondary Schools, Premier Schools, Centennial Schools, Schools in Putrajaya and Cyberjaya and Special Model Schools.

- $\quad$ Special Education Primary Schools, Special Education Secondary Schools, and Special Vocational Education Secondary Schools.

- International Schools and Private Schools.

- $\quad$ Matriculation Colleges and Institutes for Teachers Education

(Ministry of Education, 2006a, pp. 119-121).

Each of these clusters is distinguished by the diversity of their students ethnicity, cultures, languages as well as abilities, interests and potentials. Thus, the establishment of CSEs in Malaysia was aimed to cater to the diverse needs of students, particularly their abilities and talents, in order to provide the best teaching and learning process in Malaysia. 


\section{Related Literatures}

The issues of diversity among students are now one of the main concerns faced by schools around the globe. The growth of diversity in many aspects of the students' background has an effect on the schools efforts with the intention to provide and implement the best education process that can produce positive changes in students' behavior and in their academic achievement (Unruh \& McCord, 2010). The attempt to define diversity is problematic in nature as questions abound on the plausibility of an agreed upon definition. According to Webster's Online Dictionary, diversity means "the condition of having or being composed of differing elements and; the inclusion of different types of people (as people of different races or cultures) in a group or organization” (http://www.websters-online-dictionary.org/). Thus, this study will explore how the cluster schools in Malaysia are directing their attention to fulfill the needs of students who are more diverse in terms of interests, talents and abilities.

Individual's interests, talents and potential are, in reality, influenced by various factors. As stated by Social Ecological Model developed by Bronfenbrenner (1979), each person is significantly affected by interactions among a number of overlapping ecosystems such as microsystems consisting of individual or interpersonal features and those aspects of groups that comprise the social identity (Gregson, 2001). This may include roles that a person plays (for example mother, father, sister, brother and child.) or characteristics they have in common. Mesosystem are the organizational or institutional factors that shape or structure the environment within which the individual and interpersonal relations occur (Gregson, 2001). Exosystem refers to the community level influence, including fairly established norms, standards, and social networks (Gregson, 2001) and; macrosystem are the cultural contexts (Bronfenbrenner, 1979), not solely geographically or physically, but emotionally and ideologically. Therefore, we have to understand or evaluate a student in the context of his/her mesosystems (immediate family, extended family, friends, network), macrosystems (culture or subculture), and exosystems (social structures). This model places the student as a diverse learner, school staff, and parents/community in an ecological context, for a broader understanding of the critical issues affecting students from diverse backgrounds and the development of relevant service and educational models (Sanchez, 1995). For the diverse students, the ability to conceptualize and integrate culture and issues of diversity within a developmental perspective is also crucial, given the changes in developmental tasks at each life stage and the various ways that these "tasks" are expressed and resolved within various students groups (Lee, 1995). Relevant to the diverse learner in schools, these issues must be integrated within the specialized early intervention programs offered to children with developmental issues (Lynch \& Hanson, 1992). Early intervention services are an extremely important part of the total, life-stage conceptualization for low income, diverse learners because such learners are more vulnerable to developmental concerns (Sanchez, 1995).

However, Guild (2001) argues that schools at present are heavily biased towards uniformity over diversity. Most schools still function with the understanding that all students were the same. Students use the same textbooks and the same materials for learning. They work at the same pace on the same quantity of material. They study the same content and work through the same curriculum on the same schedule. Teachers talk with groups of students, delivering 
the same information consistently to everyone. And, of course, schools use the same tests for all to measure the success of the learning.

The establishment of the cluster school in Malaysia was, on the other hand, not aimed in making CSEs to be uniform, but as an intervention to enhance the excellence of the schools in accordance with the students' potential and talents. Apart from that, this approach is also important to ensure that the diversity in the Malaysian education system can cater to the diverse interests and potential, as well as the ability of students in particular areas in Malaysia (Ministry of Education, 2006b).

The practice of cluster schools in Malaysia was, in fact, adapted from the concept of school diversity which was practiced by Britain. As indicated by Department for School, Children and Families (2010), Britain has a history of diversity in education, reflecting the diverse needs and aspirations of its learners, and recognizes that the education system must be responsive and dynamic to meet the challenges of rapid regional and global changes. In Britain, there are two key principles that underpin the government's agenda for supporting the school's diversity namely: 1) Specialization: A school that builds on its individual strengths and develops a clear sense of its own ethos and character is more likely to be a successful school. The school's diversity programs promote school improvement by providing opportunities for schools to work on their strengths, enabling them to take the lead in their area of expertise and to drive innovation and; 2) Collaboration: A school's diversity has the potential to benefit all students in a community when schools work together to share their resources and expertise. As schools develop their individual strengths, and standards of teaching and learning improve they can then contribute to raising standards in the wider system (Department for School, Children and Families, 2010). These two key principles of school diversity are now being adapted and implemented by the cluster schools in Malaysia in order to cater to the diverse needs of the Malaysian children.

\section{Purpose of the study}

This study aims to examine the role of the cluster schools in Malaysia in meeting the diverse needs of students. In addition, this study also seeks to identify the efforts made by the cluster schools in managing the sustainability of their niche areas to be in line with their students' needs.

In particular, this study intends to answer these research questions:

a) What are the roles of niche areas in catering to the diverse needs of students?

b) What are the Malaysians' cluster schools efforts in enhancing the students' excellence?

c) How was the monitoring process by the MoE Malaysia?

\section{Methodology}

This exploratory research used qualitative methods including a document review and focus groups to gather data. The use of these two techniques permitted triangulation of the data to improve the validity of the findings, and enabled greater inferences from the results. 
According to Fraenkel and Wallen (1996), the analysis of documents can help researchers to get the data objectively through the documents and does not require the presence of the informants. In this study, some relevant documents were analyzed, namely: Certification of Leadership and Management, Management Certification, Curriculum Certification, Niche Area Certification, the selected CSEs strategic plan and reports on of their programs and activities.

Interviews were used to gather information related to individual's experiences, views and reactions (Merriam, 2001). In this study, a total of six Malaysian CSEs with different excellent clusters were selected for the interview. Two sources were used for selecting interviewees, the first was schools in the first cohort of CSEs recognition and, second, every school is a representative of different cluster. To facilitate the data analysis process, each school was given a different code according to their type of cluster. Table 1 shows the codes of the six CSEs:

Table 1 . The codes of the cluster schools

\begin{tabular}{|l|l|}
\hline CSE1 & Religious school \\
\hline CSE 2 & Premier boarding school \\
\hline CSE 3 & Boarding school \\
\hline CSE 4 & Special education school \\
\hline CSE 5 & Indigenous school \\
\hline CSE 6 & Tamil national-type school \\
\hline
\end{tabular}

A focus group interview was conducted with a group of administrators of each school to obtain information regarding the research questions.

\section{Findings}

The findings of this study are detailed in three main research purposes: to examine the role of the niche areas in meeting the diverse needs of students; to identify the efforts that cluster schools carry out in managing their niche areas in line with their students' needs, and; the monitoring process by MoE Malaysia.

\subsection{The role of niche areas in catering to the diverse needs of students}

One of the key roles of CSEs is to ensure that the diversity in the Malaysian education system can cater to the diverse interest and potential, as well as the ability of students in particular areas. Based on relevant documents analysis and interviews, this role is carried out through the niche area of each school. As stated in Niche Area Certification and Curriculum Certification, every CSE in Malaysia must have their own niche areas. According to respondents, the niche areas of each CSE were selected based on their students' excellent achievement in academic, co-curricular or personality areas. Thus, each of the CSE will have different niche areas from one another.

The interviews and documents analysis also show that the niche areas are the showcase of each CSE to help schools enhance their students' talents and to distinguish them from the non CSEs in Malaysia. The interviews also indicated that the vital purpose of establishing the niche areas 
for each CSE was an effort for students' character development. For example, CSE2 had chosen leadership as well as playing rugby and language as their niche areas. According to CSE2,

... there are various elements of leadership, namely towering personality, developing towering personality and the techniques of collaborating with community; for instance communication aspect, team building skills and strategic thinking. And from my point of view, the aspects of leadership are also being in the rugby games and language.

In addition, the data from CSEs strategic plan and reports also show that they have organized various programs and activities to enhance students' excellence in the particular niche areas. There are also programs and activities that have been initiated by the students at national as well as international levels. CSE2 commented that,

... to develop students, the school management must give space and opportunity for students to plan, manage and control the events and activities either at school, national and international levels. Moreover, my school has organized the Malay College Youth Summit twice since 2008, involving many countries throughout the world. In this event, students themselves organized the whole event and the teachers acted as the facilitators in their respective parts. This program plays an important role in improving students' confidence and leadership capacity.

As indicated in CSE strategic plans, niche areas play the crucial role in catering to the students' needs. For this reason, all CSE should select their niche areas based on their students' abilities and potential. Typically, the areas have been selected based on the schools' outstanding achievement, i.e. record of students' performance in competitions which they participated at national and international level, for three consecutive years. As explained by CSE3,

... the first step in selecting our niche area was analyzing the school achievement in academic and extra-curricular areas. Then, based on the achievement, my school selected and forwarded to MoE three outstanding areas as our niche areas.

This process indicates that the interests and capabilities of students in cluster schools are tailored with the creation and selection of different niche areas for each school. This idea was also supported by CSE6, where the selection of their niche areas was based on the past performance results at national level. According to CSE6,

We had participated in badminton and zapin dance (a kind of Malay traditional dance) at national level and had an outstanding achievement. Furthermore, this is something to be proud of because all of our students are Indian but able to perform the 
Malay traditional dance perfectly. Based on the achievements, we have chosen these two areas as their niche areas.

The interviews also revealed that the CSE have been gone through a similar process in selecting their niche areas. Most of the schools begin their selection process with the school committee discussion before deciding the most suitable niche areas for their schools. As stated by CSE3,

... the early stages of the selection process began with a discussion between the principals and teachers at school level. The principal and the school middle managers will discuss pertaining to the areas that are seen as our potential niche areas. After deciding on the three selected niche areas, we need to propose and justify our decision to the MoE.

However, for CSE2, which is a premier as well as fully residential school, this selection process also received inputs from their former students via an organization which is known as Malay College Boy Association (MACOBA). According to CSE2,

MACOBA is a non-government organization (NGO) and was established by CSE2's former students. It is very influential in some decision making process, for instance in the CSE2's niche areas selection.

This indicates that in certain circumstances, CSE2 is responsible to get their stakeholders' opinion (i.e. MACOBA) in order to implement activities or programs on leadership aspects or their other niche areas. In addition, the finding proves that the voice of school stakeholders was also taken into consideration in selecting the niche areas of the cluster schools to ascertain that the students' diverse needs are met.

\subsection{The Malaysian cluster schools efforts in enhancing the student excellence}

As a type of an open system organization, the cluster schools should be expanded and developed in tandem with the development needs of the environment. There are numerous efforts that have been planned and implemented by CSEs in improving their respective niche areas. These efforts incorporate programs and activities to develop the students' academic achievement, potential as well as their talents and teachers' professional development. All these programs and activities, however, must be approved by the MoE before they could be implemented by the respective schools.

The efforts and actions can be divided into the following three aspects, namely:

\section{i. External experts training}

Apparently, CSEs were given the autonomy to appoint the best coaches and expert (as they perceived) using the allocation to accelerate their niche areas excellent. Due to this, all respondents were agreeable that their schools had chosen their own coaches for areas that require external expertise. According CSE2: 
Experienced teachers will handle everything. But, not all the issues they can handle. There are certain programs or activities conducted by coaches from outside. If we feel that we need expertise from outside, we will hire and appoint them.

The explanation of CSE3 also supports the statement of CSE2. According to CSE3,

In terms of activities we have autonomy but it up to schools to implement anything that could propel the niche areas. For example, we appoint a coach to train the debater team to strengthen the school debater team. And, we also invite the music experts, for example, experts from Singapore. We invited them and we organized a three-day workshop just to learn music for example Cak Lempung (a kind of Malay traditional music) and others. So we have the autonomy to bring the expert to conduct the workshop for students.

CSE6 explanation also supports the acquisition of the cluster school autonomy in selecting their coaches.

In badminton training (one of CSE6's niche areas), around two hundred students were trained by three external coaches with the payment of RM2000 per month. The training was conducted every Sunday at nearest nearby stadium and run by the coaches.

Findings indicate that coaches invited by the school were not only training the students but also the teachers who are directly involved in the niche areas. This training is very important since the teachers will continue to train the students after the coaches' leave. In addition, as the numbers of students are too huge for the coaches to provide the best training, only the selected talented students were trained under external coaches while others will be trained by the teachers.

Based on the interviews, the study reveal that each CSE received an amount of RM500,000.00 (approximately USD 161,681.44) for niche areas development programs and activities. The amount was above the standard allocation for every school in Malaysia. The provisions were used by schools to strengthen their individual niche areas via programs and activities such as training, workshops and seminars, and purchasing related equipment. Hence, it allows CSEs to hire external coaches in providing the best training for their students.

\section{ii. Collaboration with external institutions}

According to CSEs' administrators, one of the significant autonomy components of the CSEs is developing collaboration with external entities, particularly higher education institutions (HEIs) from local and abroad. The principle of this networking is to obtain views and inputs from the experts to enhance the students' excellence especially in particular niche areas. CSEs' administrators proclaimed that the collaborations were built as a result of memorandum of understanding (MoU) between CSEs and HEIs. Several of these MoUs were initiated by MoE. 
Once identified, the selected institutions will be required to help the CSEs propel their excellence in respective niche areas. For example, the MoU with external entities such as RECSAM (Regional Centre for Education in Science and Mathematics) provide many benefits to some CSEs with the intention of improving the skills of students and teachers in the science and technology. Moreover, the HEIs will provide assistance in the form of expertise, resources and facilities to schools without imposing charges.

Besides experts from local HEIs, CSEs also obtained advice and inputs from international HEIs experts. As reported by CSE1,

... a group of experts from Australia, UK, New Zealand and Singapore came to our school and shared ideas and experiences and conducted related research as well. The visit provided our school an opportunity to obtain feedbacks from the experts regarding the management practices of the school as well as innovations on teaching and learning.

The collaboration between Malaysian cluster schools and overseas HEIs were linked to agreements between Malaysia and the foreign governments. All CSEs agreed that:

\section{.... the MoU between Malaysia and other countries (government to government - G to G), such as Australia, Thailand and Indonesia play an important role in building cooperation between the cluster schools in Malaysia with the schools and institutions of higher learning abroad.}

Apart from MoUs, collaboration can also be developed through events organized by students, as practiced by CSE2, who organized the Malay College Youth Summit, at international level. Organizing such an event is a major platform for CSE students to share their ideas with other teenagers from around the world. According to the CSE2 administrators, this program exposed the students to plan, manage and operate their events and activities with the assistance of teachers who acted as facilitators. This event was attended by participants from various neighboring countries, for example Singapore, Indonesia, Thailand, Philippines, and India. The notification of this summit was communicated through various means, including the school's website, brochures and advertisement. The school teachers who attended the international conference also played their role in disseminating the brochures. In addition, CSE2's administrators explained that;

... the organization of the event used the special financial allocation for cluster schools that focus on the niche area of student leadership development.

The experience by the students in organizing the event provides them with opportunities to develop their leadership skills as well as enhances their school’s excellence.

iii. Teachers' professional development 
The efforts for ensuring the success of CSEs are not only focused on the development of students but also on the professional development of teachers and school leaders. The professional development is focused on the understanding of teachers' main roles in enhancing their schools' performance as they are the 'key players' of the process. The respondents explain that the programs and activities in heightening CSEs performance will be successful with the teachers' cooperation and support. Thus, the teachers must develop their professionalism with continuous staff development program that are provided by the schools.

The findings show that the professional development of cluster school teachers was conducted by the following methods;

a) Training and lectures 'through in-service' training program. Usually, the training is conducted by invited external experts and emphasized on the efforts of improving the niche areas of the school. The 'through in-service' training (IST) program is a must for all Malaysian schools. These programs are organized at least four times per year by each school. There are also trainings that take place during staff meetings. These trainings are considered as a platform to create awareness and also to disseminate knowledge to all teachers regarding the development of their schools. Knowledge and sensitivity are very important in helping teachers play significant roles in all school activities.

b) 'Benchmarking visit' to outstanding schools in particular areas, local and abroad. As a result, teachers can learn from the experienced schools in conducting programs and activities in providing the best platform for the students to accelerate their talents.

However, the respondents stated that the professional development programs were not only given to the teachers who are directly in charge of the niche areas, but also to all teachers in the school. It is necessary since the performance of the cluster schools does not merely depend on a few teachers, but requires cooperation from everyone in the school. By participating in the professional development program, all the teachers will be aware of the aspirations and goals of excellence of the school.

\subsection{The monitoring process by the Ministry of Education Malaysia}

Based on interviews, findings were show that the progression of all activities and programs in CSE are monitored from time to time by certain sections of the MoE Malaysia. Based on the respondents' description, the process of monitoring can be divided into two types, specifically: regular monitoring which is usually carried out on all schools in by the Inspectorate General, and state auditor and; a special monitoring for CSEs only by the Cluster School Division and Cluster of Excellence Advisory Board. CSEs, in addition, are also responsible for submitting reports of their programs and activities implemented relating to their niche areas for monitoring purposes. This action is aimed in ensuring that CSEs always comply with the guided autonomy standards set by the MoE Malaysia in fulfilling the diverse needs of students. 


\section{Discussion and Conclusion}

The establishment of CSEs is to accelerate the performance of selected education institutions in the education system of Malaysia. In this context, the word 'performance' is focus on academic and non-academic activities achievement that are related to the students' talents and abilities. As argued by Boethel (2003), school performance is not solely based on students' academic achievement, but also the effectiveness of schools in improving the talent and potential of its pupils as expected by parents and local communities.

As a whole the findings from this study prove that the establishment of CSEs in Malaysia does is not only heightened the organizational excellence per se, but also focused on the diverse needs of the students particularly on talents and abilities. The findings showed the niche areas of each CSE play important role in enhancing the students excel. The niche areas were chosen based on CSEs' students' performance at national and international levels. Indeed, the performance of each CSE was distinguished by their students' interest and propensity and this has an impact in the niche areas selection process. Thus, the niche areas are the showcase of CSEs too. Apart from that, the niches areas have also established specialization element in each CSE as practiced by school diversity in Britain (Department for School, Children and Families, 2010). According to Ministry of Education (2006a), the efforts in improving school performance is conducted by generating clusters of excellence in education according to specific areas (niche areas) schools respectively because there are different types of school in the education system in Malaysia. In order to provide and implement the best education process that can produce positive changes in students' behavior and in their academic achievement we have to understand or evaluate them in the context of his/her ecosystems, as suggested by SEM (Sanchez, 1995).

This study also showed that there were various efforts to enhance the potential and talent of students in the CSE, particularly in its niche areas. They are given the autonomy in doing so i.e. designing programs and activities; appoint external experts and trainers for their students in order to accelerate niche areas excellence; collaborate with HEIs, local and abroad; and organize teachers' professional development. These efforts were undertaken in order to enhance the excellence of their schools in accordance with the students potential and talents (Malaysia, 2006).

Based on findings, this study proved that the establishment of CSEs in Malaysia had fulfilled the diverse needs of students, particularly in terms of their potentials and talents. This was conducted by the creation of niche areas in each CSE, the efforts of the schools and the MoE Malaysia to ensure the needs of diverse students can be achieved via these niche areas.

\section{Acknowledgement}

The study reported in this article was funded by Universiti Sains Malaysia research grant entitled "The Development of Decentralization Inventory as Practiced in Malaysian Cluster Schools". 


\section{References}

Boethel, M. (2003). Diversity School, Family \& Community Connections. Annual Synthesis 2003. National Center for Family and Community Connection with schools (SEDL): Texas.

Bronfenbrenner, E. (1979). The ecology of human development. Cambridge, MA: Harvard University Press.

Caldwell, B.J. (2005). School-based Management. IIEP: International Academy of Education.

Cuttance, P. (1990). Performance Indicators and the Management of Quality in Education. Keynote Address prepared for the National Conference on Indicators in Education ( $3^{\text {rd }}$, Canberra, Australia, December 3-4, 1990).

Department for School, Children and Families. (2010). What Is School Diversity? [Online] Available:

http://www.standards.dfes.gov.uk/schooldiversity/what_is_school_diversity/?version=1 July 2010).

Dykstra, A.H., \& Kucita, P. (2008). School-based Management through Cluster Schools: A Case Study from Cambodia. [Online] Available: http://www.eric.ed.gov/ (13 September 2009).

Fagerlind, I., \& Saha, L. J. (1989). Education and national development. Oxford: Pergamon

Fraenkel, J.R., \& Wallen, N.E. (1996). How to design and evaluate research in education (4th ed.). New York: McGraw-Hill, Inc.

Gregson, J. (2001). System, environmental, and policy changes: Using the social-ecological model as a framework for evaluating nutrition education and social marketing programs with low-income audiences. Journal of Nutrition Education, 33(1), 4-15. http://dx.doi.org/10.1016/S1499-4046(06)60065-1

Guild, P.B. (2001). Diversity, Learning Style and Culture. October 2001 New Horizons for Learning. [Online] Available: http://www.newhorizons.org/ (22 Sept 2010).

Lee, C. C. (1995). A school counseling and cultural diversity: A framework for effective practice. In C. C. Lee (Ed.), Counseling for diversity: A guide for school counselors and related professionals (pp. 3-17). Boston: Allyn and Bacon.

Malaysia (1979). Cabinet Report. Kuala Lumpur: Education Ministry of Malaysia.

Malaysia (2006). $8^{\text {th }}$ Malaysia Plan. Kuala Lumpur: National Publication

Merriam, S.B. (2001). Qualitative research and case study applications in education. San Francisco: Jossey-Bass Publisher.

Ministry of Education. (2006a). Education Development Master Plan (EDMP) 2006-2010. Putrajaya: Education Ministry of Malaysia.

Ministry of Education. (2006b). Cluster School. [Online] Available: 


\section{Macrothink}

International Journal of Education

ISSN 1948-5476

2011, Vol. 3, No. 2: E20

http://www.moe.gov.my/?act=search\&id=0\&keyword=sekolah+kluster (25 October 2009).

Sanchez, W. (1995). Working with Diverse Learners and School Staff in a Multicultural Society. [Online] Available: http://www.eric.ed.gov (21 ${ }^{\text {st }}$ June 2010).

Unruh, L.E., \& McCord, D.M (2010). Personality traits and beliefs about diversity in pre-service teachers. Individual Differences Research, Volume 8, Issue 1, March 2010, pp. $1-7$.

Webster Online Dictionary (2010). http://www.websters-online-dictionary.org/

\section{Copyright Disclaimer}

Copyright reserved by the author(s).

This article is an open-access article distributed under the terms and conditions of the Creative Commons Attribution license (http://creativecommons.org/licenses/by/3.0/). 